NIST Technical Note 1779

\title{
General Guidance on Emergency Communication Strategies for Buildings
}

\author{
Erica D. Kuligowski
}

http://dx.doi.org/10.6028/NIST.TN.1779

National Institute of Standards and Technology

U.S. Department of Commerce 


\section{General Guidance on Emergency Communication Strategies for Buildings}

Erica D. Kuligowski

Fire Research Division

Engineering Laboratory

http://dx.doi.org/10.6028/NIST.TN.1779

February 2013

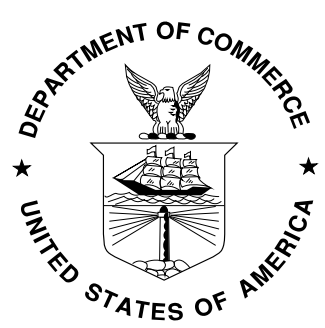

U.S. Department of Commerce Rebecca Blank, Acting Secretary

National Institute of Standards and Technology Patrick D. Gallagher, Under Secretary of Commerce for Standards and Technology and Director 
Certain commercial entities, equipment, or materials may be identified in this document in order to describe an experimental procedure or concept adequately. Such identification is not intended to imply recommendation or endorsement by the National Institute of Standards and Technology, nor is it intended to imply that the entities, materials, or equipment are necessarily the best available for the purpose.

National Institute of Standards and Technology Technical Note 1779 Natl. Inst. Stand. Technol. Tech. Note 1779, 39 pages (February 2013) 


\section{Acknowledgements}

The U.S. Department of Homeland Security, Science and Technology Directorate sponsored the production of this material under Interagency Agreement HSHQDC-07-X-00723 with the National Institute of Standards and Technology. The author would also like to thank the Fire Protection Research Foundation (FPRF) for sponsorship of the Project Technical Panel. The members of the Technical Panel are listed here:

- Kathleen Almand, Fire Protection Research Foundation

- Oded Aron, Port Authority NY and NJ

- June Ballew, Cooper Notification

- Don Bliss, $\mathrm{NI}^{2}$ Center for Infrastructure Expertise (NH)

- Bob Boyer, UTC Edwards

- Robert Chandler, University of Central Florida

- Joe Collins, Dallas Fort Worth airport

- Rita Fahy, National Fire Protection Association's Fire Analysis and Research Division

- Daniel Finnegan, Siemens Fire

- Dave Frable, U.S. General Services Administration

- Denis Gusty, U.S. Department of Homeland Security

- Edwina Juillet, NFT/LSPwD

- Matthew Kelleher, Montgomery County Fire \& Rescue

- David Killian, Walt Disney Parks and Resorts

- Amanda Kimball, Fire Protection Research Foundation

- Scott Lacey, Lacey Fire Protection Engineering

- Chris Maier, National Weather Service

- Derek Mathews, Underwriters Laboratories

- Philip Mattson, U.S. Department of Homeland Security

- Dennis Mileti, University of Colorado

- Wayne Moore, Hughes Associates, Inc.

- Rodger Reiswig, SimplexGrinnell

- Lee Richardson, National Fire Protection Association’s staff liaison

- Robert Schifiliti, RP Schifiliti and Associates

Guidance from the Technical Panel, as well as NFPA 72's Emergency Communications Systems Technical Committee, was integral in the development of this document. Thank you to the authors of NIST Technical Note 1733 (Steven Gwynne, Kathy Butler, Bryan Hoskins, and Carolyn Sandler). Also, thank you to Richard Peacock, Thomas Cleary, and Anthony Hamins for their review of the document before publication.

Thank you to the Industry Project Sponsors: Siemens Industry, Inc., SimplexGrinnell, Underwriters Laboratories, Inc., and xMatters, as well as to the Contributing Industry Project Sponsors: Bosch, Cooper Notification, and United Technologies. 


\section{Executive Summary}

When a building emergency occurs, it is not always sufficient to simply initiate alarm bells. Individuals may not know what the alarm bell means and as a result may respond inappropriately to its sound. Many buildings have installed mass notification or emergency communication systems, based upon requirements provided in international codes and standards, that can be used to disseminate audible or visually-provided information in the event of an emergency. However, there is a lack of guidance on how to use current emergency communication systems in the most effective manner. For example, buildings often use these systems to disseminate pre-recorded, general emergency voice alarm messages that leave occupants wanting and needing further information before effectively responding. Especially as the use of newer technologies such as mobile devices or social networking tools grows, guidance on message content and dissemination becomes even more critical to ensure effective and safe response of building occupants during an emergency.

The purpose of this report is to provide general guidance to building managers and/or building emergency personnel responsible for emergency communication on how to create and disseminate messages using basic communication modes (audible vs. visual technology). The guidance provided here is based on the review of 162 literature sources from a variety of social science and engineering disciplines (Kuligowski et al. 2012) and the prioritization of the specific findings extracted from each literature source. This document describes the process in which people receive and process information in order to take action during emergencies. Then, the document presents guidance on how to create and disseminate emergency information in the face of rapid-onset disasters - providing guidance on the dissemination of alert signals, the creation of the warning message, the formatting of messages for both visual and audible means, and the dissemination of the warning message. The document ends with a discussion of research questions still left unanswered, and future efforts necessary to complete a comprehensive document on emergency message creation and dissemination for building disasters. 


\section{Table of Contents}

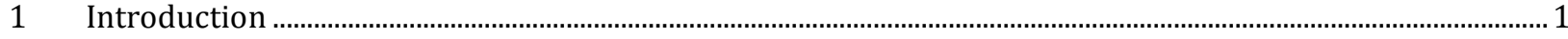

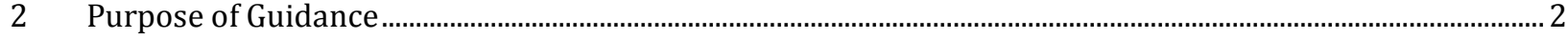

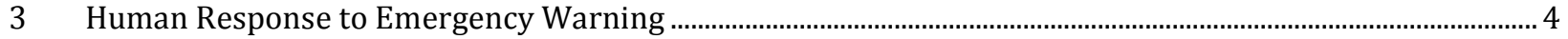

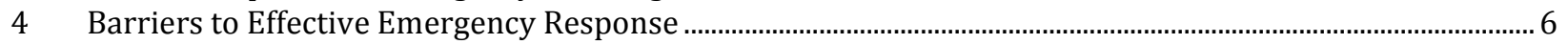

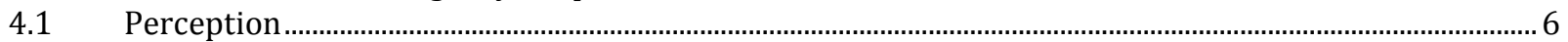

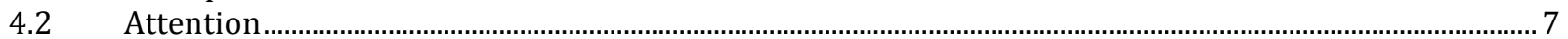

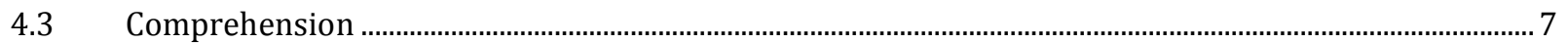

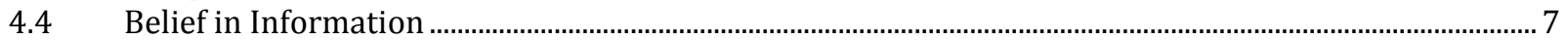

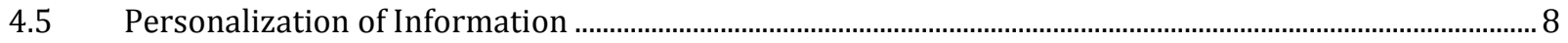

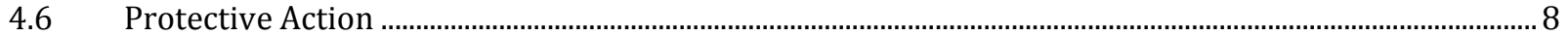

5 Guidance on Emergency Communication Strategies for Buildings …..........................................................

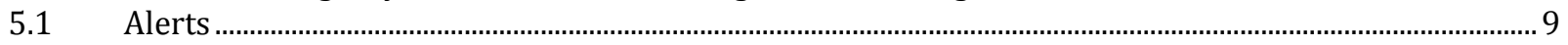

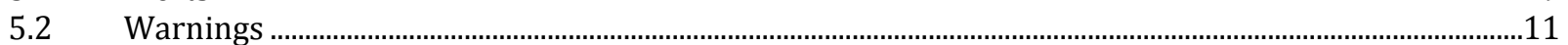

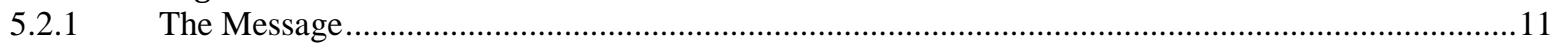

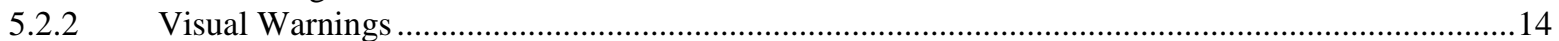

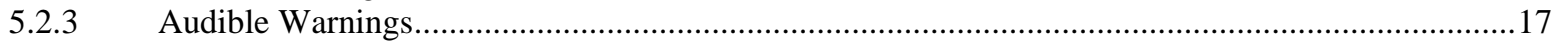

5.2.4 Dissemination of the Warning Message .......................................................................... 19

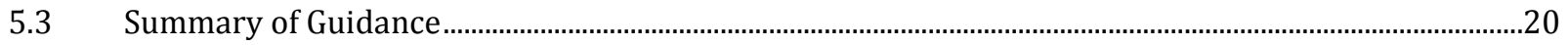

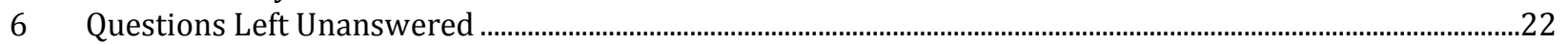

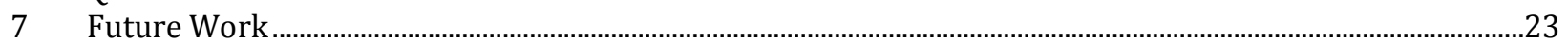

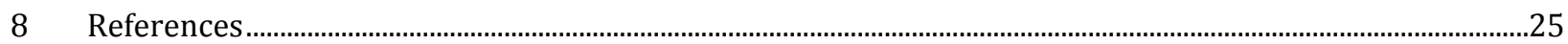




\section{Introduction}

Until very recently, it was widely assumed that telling people about an emergency incident would lead to panic (Tierney 2003; Quarantelli and Dynes 1972). This assumption was commonplace, both with the lay population and with many emergency responders. The view that people would panic in response to an incident (and specifically to information describing the incident) influenced both the notification procedures employed and the language used to report the incident response behavior. This assumption influenced a difficult and harmful cycle consisting of the following steps: people report that they had panicked, emergency officials continue to believe that panic is a normal response, emergency information is withheld in the next disaster, human response is delayed and inefficient, the situation becomes more dire, and human response becomes more desperate.

It is now broadly accepted that depriving evacuees of information is more likely to lead to an inefficient and inappropriate response; e.g., misinterpreting the incident and the threat it poses, delaying their response, and ignoring safe egress routes (Mileti and Sorensen 1990). During an incident, people will seek information regarding the nature of the incident and what they should do in response to it. Unfortunately, this information may not always be easy to find, reliable, consistent or accurate.

At present, many buildings and building campuses in the United States are installing mass notification or emergency communication systems to improve communication between the building or emergency officials and the public. The National Fire Alarm and Signaling Code (NFPA 72), 2010 edition, provides requirements for the application, performance and installation of emergency communication (or mass notification) technology (NFPA 2010a). However, the 2010 edition of NFPA 72 provided little guidance on how to use these systems for effective emergency communication ${ }^{1}$. Additionally, many countries use British Standard BS 5839 -- Fire Detection and Fire Alarm Systems for Buildings - Part 8 (BS 5839-8:2008), in which chapters 20 and 21 discuss emergency messages and dissemination techniques.

In the United States, there is little guidance outside of the building codes regarding the content and dissemination strategies for emergency messages. The people providing the messages during an emergency may not have the necessary tools, techniques, guidance, and training to effectively provide information to the public when an emergency event is imminent or unfolding. This problem exists across all modes of notification, whether visual, audible, tactile, or social systems are employed. Irrespective of the mode used, it is necessary for emergency communication to be effective in order to facilitate the procedural measures employed and the desired response.

The purpose of this research project, which was funded by the U.S. Department of Homeland Security, Science and Technology Directorate, relates specifically to the effectiveness of emergency notification or communication. This document presents general guidance on emergency communication strategies to alert and warn building occupants of impending rapid-

\footnotetext{
${ }^{1}$ The newest edition of NFPA 72 (2013) provides guidance for message providers on message content, formatting, and dissemination based, in part, upon results from this project.
} 
onset events in buildings and building campuses in the United States. This guidance is based on the review of 162 literature sources from a variety of social science and engineering disciplines published in Year 1 of this research project (Kuligowski et al. 2012) and the prioritization of the specific findings extracted from each literature source.

\section{Purpose of Guidance}

This guidance document provides an understanding of human response to emergency communication and the ways in which to improve this response via more effective messages, message formatting, and message dissemination. This document begins by describing the ways in which people respond to emergency cues and information. Then, the needs of message recipients are identified. Based upon these needs, this document provides general guidance to building managers, emergency personnel, alarm system manufacturers, codes/standards committees, or others responsible for emergency communication on how to create, format, and disseminate messages to all building occupants, regardless of abilities or disabilities, using basic communication modes (audible and visual technology) ${ }^{2}$.

The focus of this guidance is rapid-onset emergencies, or those emergencies that occur with no or almost no (in the case of minutes) notice, rather than slow-onset events (i.e., emergencies in which the occurrence is known hours or even days in advance). Examples of rapid-onset events are included in Table 1. The events shown in Table 1 were selected from NFPA 1600, the Standard on Disaster/Emergency Management and Business Continuity Programs (NFPA 2010b), which lists hazards to be evaluated when planning for emergencies.

\footnotetext{
${ }^{2}$ Limited guidance is provided on the use of tactile systems due to the limited amount of research available on human response to these systems.
} 
Table 1: Potential hazards categorized here as rapid-onset incidents.

\begin{tabular}{|c|c|}
\hline Naturally occurring hazards & Human-caused events \\
\hline 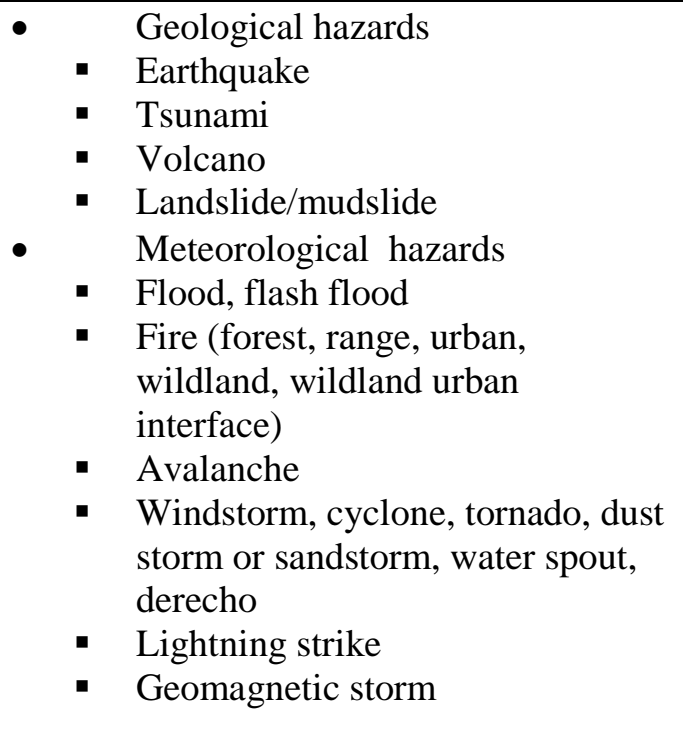 & $\begin{array}{l}\text { - Accidental hazards } \\
\text { - } \text { Hazardous material spill/release } \\
\text { - } \text { Transposion/fire } \\
\text { - } \text { Building/structure collapse } \\
\text { - } \text { Water control structure/dam/levee } \\
\text { - } \text { Inilure } \\
\text { - } \text { Terrontional hazards (chemical, biological, } \\
\text { - } \text { radiological, nuclear, cyber, arson) } \\
\text { - Civil disturbances } \\
\text { - Enemy attack, war } \\
\text { - Insurrection } \\
\text { - Physical or information security } \\
\text { - } \text { breach } \\
\text { - Workplace/school/ university violence }\end{array}$ \\
\hline
\end{tabular}

In this guidance document, recommendations are provided based upon the summary report of the literature completed in the first phase of this project (Kuligowski et al. 2012). The summary report includes individual annotations of 162 sources from a variety of social science and engineering disciplines. Additionally, over 40 pages of findings and recommendations from each of the 162 sources are listed in the summary report. Each of these findings was reviewed and prioritized using a set of criteria to develop the final set of guidance that is included in this document (Section 5). A list of the criteria used to prioritize the summary report's findings is listed here:

- Is the finding relevant to buildings and building occupants?

- Does the finding relate to emergency conditions rather than normal/non-emergency conditions?

- Is the finding in agreement with theory and expert opinion on human behavior in emergencies?

There were findings that contradicted one another. The author attempted to reconcile these contradictions by siding with findings that were most aligned with well-accepted social theory of human behavior in natural or technological disasters. Also, findings that originated from sources found in archival publications received higher priority, in cases of contradicting guidance. However, there were some contradictory findings in which consensus was not reached, and thus, were not included in this guidance document. Instead, they are discussed in Section 7 of this report, labeled as a discussion of the questions that are still left to answer.

There are also topics of interest that were included in the summary report (Kuligowski et al. 2012), however, that were deemed outside of the scope of this guidance document. The first topic that was deemed outside of the scope of this document was the mechanics of visual lighting systems for signage. Secondly, any guidance provided on the volume necessary for audible alert and warning systems was also outside of the scope of this document. Both of these topics can 
increase the perception (i.e., hearing or seeing) of the alert or warning message, and have been covered in some detail in codes/standards on mass notification systems (e.g., NFPA 72 [2013]).

This document does not provide a detailed discussion of alerting and warning technology, and similarly, does not advocate for the use of one type of technology over another. The summary report (Kuligowski et al. 2012) provides a categorization of current mass notification technology, the primary senses affected by each technology, and the pros and cons of these systems for emergency communication purposes. Therefore, it was not necessary to provide additional discussion of this topic. Additionally, since the focus of this document is to provide general guidance on the creation of the messages themselves and general dissemination techniques, the identification of any one type of technology was not required.

The follow-on document in this project (Year 3) will provide more detailed guidance on message template development, including examples of message templates, as well as ways to test these messages for specific buildings. In this future guidance document, templates will be provided based on the emergency type (rapid-onset emergencies only), and more attention will be paid to technology type and how that will affect the type of message created and methods for message dissemination.

Finally, this document will not provide specific guidance on the development of graphics to accompany alerts or warning messages. There are standards available, via NFPA (2012), ANSI (ANSI/NEMA A535 2011), and ISO (2011; 2007; 2004), especially ANSI/NEMA Z535.3 Criteria for Safety Symbols (ANSI 2011), that provide guidance on the development of graphics for static or dynamic signage. The main focus of this guidance document is the textual message content, and thus, interested parties developing a pictogram or symbol for emergency communication should seek guidance from the standards listed above.

\section{$3 \quad$ Human Response to Emergency Warning}

In contrast to the panic model previously assumed, the response of an individual during an incident can be better characterized as a decision-making process in which people receive information from their environment, interpret that information, and respond based upon their interpretations (Lindell and Perry 2004). Understanding this process and the factors that influence certain interpretations can aid in the development of better guidance on emergency messages and dissemination systems.

Over the last 50 years, numerous empirical studies have sought to systematically chart the social processes involved in human responses to emergency incidents (Tierney, Lindell and Perry 2001; Mileti and Sorensen 1990; Drabek 1986; Drabek 1969). Of these, the Protective Action Decision Model (PADM) is selected here to structure the guidance offered (Lindell and Perry 2004). The PADM provides a framework that describes the information flow and decision-making that influences protective actions taken in response to natural and technological disasters (Lindell and Perry 2004), and has been recently used to analyze behavioral response to the 2001 World Trade Center disaster (Kuligowski 2011). 
Specific to public warnings and emergency information, the PADM asserts that the process of decision-making begins when people are first presented with cues, e.g., warning messages. The introduction of these messages initiates a series of processes that must occur in order for the individual to perform protective actions, split into pre-decisional processes (PRE-DEC, which determine whether a decision-making process commences), and decisional processes (DEC - the key components of the decision-making process itself). A simplified version of this process is presented below

- PRE-DEC_1: the individual must perceive or receive the cue(s); e.g., a visual signal must be seen.

- PRE-DEC_2: the individual must pay attention to the cue(s); i.e., given that it is possible for the signal to be seen, the occupant actually takes note of the signal.

- PRE-DEC_3: the individual must comprehend the cue(s) and the information that is being conveyed; i.e., given that the signal is noted, that the information is understood.

- DEC_1: the individual must feel that the incident suggested by the cues and/or information is a credible threat.

- DEC_2: the individual must personalize the threat (i.e., feel that the incident is a threat to them) and feel that protective action is required; i.e., something needs to be done.

- DEC_3: the individual searches for what this action might be and establishes options.

- DEC_4: the options identified are assessed (given the information available) and a final action selected.

- DEC_5: the individual determines whether the protective action needs to be performed immediately.

Initially, the individual needs to receive a cue, pay attention to it, and comprehend the meaning associated with the cue (i.e., that it indicates an event). These represent the three pre-decisional stages of the PADM (PRE-DEC1-3) - the stages that determine whether external information is processed such that it can inform the decision-making process (Lindell and Perry 2004). Given that this information is processed, it then needs to be assessed to determine whether the information provided is credible (DEC_1). At this stage, the individual decides if there is actually something occurring that may require action, sometimes referred to as warning belief (Mileti 1974). If the individual's answer is yes, then he or she is said to believe the threat, and subsequently moves on to consider the next question in the process.

The individual next tries to determine whether the threat is relevant to him/her (DEC_2), known as personalizing the threat (or risk). Research has shown that a person's perception of personal risk, or "the individual's expectation of personal exposure to death, injury, or property damage" is highly correlated with his/her response to the disaster (Lindell and Perry 2004:51). In this stage, also known as personalizing risk (Mileti and Sorensen 1990), the individual determines the likelihood of personal consequences that could result from the threat and asks the following: "Do I need to take protective action?" Essentially, at this point, which is also discussed in human factors research as "situation awareness" (Groner 2009), the individual tries to gain insight on the potential outcomes of the disaster and what those potential outcomes mean to his or her safety. The more certain, severe, and immediate the risk is perceived to be, the more likely the individual is to perform protective actions (Perry, Lindell and Greene 1981). If the cues are 
deemed to relate to them, the individual then determines whether it is relevant and pressing. This then requires the individual to determine the nature of the response required at that point in time.

At this stage, the individual engages in a decision-making process to identify 1) what can be done to achieve protection, and 2) the best available method for achieving protection. This consists of a search for protective actions (DEC_3), and the outcome of this stage is a set of possible protective actions from which to choose. After establishing at least one protective action option, an individual engages in protective action assessment (DEC_4). This involves assessment of the potential option(s), evaluating the option(s) in comparison with taking no action and continuing with normal activities, and then selecting the best method of protective action.

Passage through these stages is often problematic. For example, information received can be incomplete, ambiguous, or contradictory, causing uncertainty in what is going on and what do to about it. If at any stage the individual is uncertain about the answer to a question, s/he engages in additional information-seeking actions. The greater the ambiguity involved in the situation, the more likely that individuals will search for additional information that can guide their actions, delaying protective action/behavior.

\section{$4 \quad$ Barriers to Effective Emergency Response}

In addition to the possible lack of appropriate emergency information, there are additional barriers that can interrupt each stage of this process, delaying protective action. These barriers will be described here, organized by the stage in the decision-making process in which they introduce difficulty.

\subsection{Perception}

In the first stage of the decision-making process, occupants need to perceive the warning information before they decide to take action. However, there are individual factors that can inhibit this process, including hearing impairments, visual impairments, and situational conditions (such as sleeping; especially for children, older adults or those who are drug/alcohol impaired) that can inhibit an individual from receiving emergency information (Gwynne 2007). The needs of these groups of individuals should be taken into account when designing an emergency communication system, so that the alerts and messages are received by the entire population, not just by those who are unimpaired and alert/awake. Additionally, all individuals, regardless of disability, can fall subject to disaster-induced factors, such as selective perception and stress (Timmons 2009; 2007). Selective perception is when an individual only perceives/receives certain elements of the environment, which can prohibit them from hearing or seeing emergency information. In a similar way, stress has been found to narrow an individual's field of perception so that they also may miss important emergency information.

Environmental factors can also inhibit individuals from perceiving emergency information. Visual and audible “pollution”, including physical obstacles (e.g., non-emergency signage) or competing sounds or noises, may cause individuals to miss messaging. Additionally, environmental cues from the emergency (i.e., smoke or flames from a fire, loud sounds, or a 
chemical agent that affects vision), dust, glare, veiling reflections, and ambient illumination may also negatively affect perception of emergency information.

\subsection{Attention}

The second step in the decision-making process is that individuals must pay attention to the information that they receive. There are certain states in which individuals may find themselves at the time of an emergency that can hinder their ability to pay attention, including drug/alcohol impairment, cognitive impairment and sleep deprivation. Additionally, individuals may be so involved or committed to certain pre-emergency activities, that they may miss cues indicating an emergency is taking place. Similarly, if they are part of a larger group, they can be less likely to pay attention to their external environment.

The environment itself can introduce factors that hinder attention. The building may be equipped with audible and/or visual distractions, making it difficult to distinguish a new cue (to which they must pay attention) from all others. This can be especially difficult for individuals who have become habituated to their environment and the cues around them.

Similar to perception, disaster-induced factors can inhibit attention paid to emergency information. Stress and anxiety brought on by the emergency can narrow an individual's focus on certain details, and once the focus is narrowed, unexpected features are simply not noticed (known as inattentional deafness or blindness) (Timmons 2009; 2007).

\subsection{Comprehension}

The third step in the decision-making process is comprehension, or understanding the information provided by the emergency communication system. Individual factors that can inhibit comprehension include untrained or unprimed individuals, age (children), non-native speakers (especially those who do not speak the native language at all), individuals with a cognitive impairment, and individuals from different cultural backgrounds than the United States. Even more complicated is the influence of stress (induced by the emergency) on the general public's ability to understand emergency information. Verbal comprehension has been found to drop an average of four grade levels at high levels of stimulation, stress and distraction (all factors that are possible during a building emergency) (Chandler 2010).

\subsection{Belief in Information}

In the fourth step, individuals are required to believe the information before they are able to act upon it. One of the main barriers to belief is normalcy bias (Drabek 1986; Okabe and Mikami 1982). Normalcy bias is the belief or assumption that nothing is happening to place the individual at risk. Regardless of the intensity of cues or information received from an emergency, the frequent initial assumption by building occupants is that nothing is going wrong. Additionally, the more people who believe this assumption, and in turn, do not act or take protection, the less likely others around them will take protection as well.

The source of the information is important in providing credibility to the emergency information. However, trusted sources for the majority of a building population may not be effective for 
minority or sub-group populations. One example of this is the distrust by minorities of government agencies during community disasters. These same inhibitions of credibility may be found in building emergencies as well.

Finally, the prevalence of false or unwanted alarms/messages in a building may inhibit response in the next building emergency. The alarm/warning system may lose credibility if it has initiated multiple times in instances when no emergency has materialized or occurred.

\subsection{Personalization of Information}

Once building occupants perceive credibility associated with an event, they must personalize the risk to themselves before taking action. The main barrier to this step is optimism (or optimistic) bias (Kunreuther 1991). In this case, individuals are inclined to believe that even though an event may be happening in their building, no danger or harm will happen to them. Most individuals, especially after initial awareness, consider this bias as reality.

Additionally, the lack of information regarding the emergency can hinder personalization of risk. For instance, if individuals do not understand or know what is going on in the building, i.e., the extent of the emergency, they are unable to develop a sense or perception of risk. Similarly, if they are not told or advised of the negative ways in which the emergency could affect them, they are again unable to develop an understanding of the dangers the emergency poses to them.

\subsection{Protective Action}

Once occupants have gone through the pre-decisional and decisional processes of the emergency decision-making process, they consider options for action, choose one, and decide when to act. However, like all other stages, there are factors that inhibit this process as well.

First, individual factors can inhibit the actions that building occupants consider and then eventually decide to take. These individual factors can include physical impairments, economic restrictions (e.g., lost pay due to missing work), and lack of training or understanding of the procedure (Lindell and Perry 2004).

Certain elements in the environment can also inhibit action. Occupants are likely to make actionbased decisions based upon the environment. For example, if routes are blocked due to environmental conditions, that may inhibit protective action decisions. Additionally, if others in the environment are not taking action, this may influence others to follow suit (even though they may wish to act). Fear of social embarrassment has been found to influence protective action in various types of research settings (e.g., Latane and Darley 1970).

Finally, disaster-induced factors can inhibit action. In very serious conditions, building occupants may be injured, which affects their ability to take protection during an emergency.

There are ways, however, to overcome these barriers to effective response in emergencies. The next section will provide guidance on emergency communication strategies to improve occupant response in building emergencies. 


\section{Guidance on Emergency Communication Strategies for Buildings}

The main way to overcome barriers in taking protective action is to improve emergency communication in building emergencies to prompt safe and effective occupant response in disasters. This section provides guidance for building managers, emergency personnel, alarm system manufacturers, codes/standards committees, or others responsible for emergency communication on the ways in which alerts and warning messages should be created, formatted, and disseminated. This guidance is based on a consensus of the emergency warning literature as well as social theory and expert opinion on human response to emergency information in disasters. This section is divided in two main parts: guidance on alerts and guidance on warning messages. Although these two parts often get confused, it is important to distinguish between the purpose of an alert and a warning message. An alert is simply meant to grab peoples' attention that an emergency is taking place and there is important information that will be provided to them. The purpose of a warning message is to give that important information to building occupants. Guidance on both alerts and warnings are provided here.

\subsection{Alerts}

Overall, the literature suggests that it is imperative to disseminate an alert to let building occupants know that a warning message will follow. Regardless of whether the warning message is provided audibly, visually, or via tactile means, an alert is necessary to gain people's attention and should be provided separately from the warning message.

An alert in a building can take many forms. For audible messages, a sound or series of sounds can be provided ${ }^{3}$. Additionally, a word or series of words can be audibly provided. In either case, the important aspects of alerts are that they significantly differ from ambient sounds (Edworthy 1998). Additionally, the building should reduce background noise when initiating audible alerts, and especially eliminate competing voices when disseminating audible alert messages (e.g., Mayhorn 2005; Edworthy 1998).

There are many examples in the literature of audible alerts. Research has identified specific signals that work in different situations/circumstances. For example, the traffic research literature has identified an attention-demanding signal that consists of modulation between 1 and $3 \mathrm{~Hz}$. In this example, the signal should be no longer than five seconds in duration, followed by 0.5 seconds of silence, before the warning message begins (Dudek et al. 1978). Other research advises the use of pulses that not only can achieve attention, but also achieve a perception of urgency (Haas and Edworthy 1996; Haas and Casali 1995). The purpose of this document is not to suggest that one audible alert type is better than another. The examples provided come from different fields, none of which have been tested in building-wide, rapid-onset emergencies. Some

\footnotetext{
${ }^{3}$ NOTE: No guidance is provided in this document on the sound levels for audible alerts. NFPA 72 (2013) provides requirements on the sound levels for audible alerts, including the sound levels for waking people up and the appropriate location of these audible alerts systems within the building to achieve an appropriate sound level result.
} 
fire researchers have also advocated for the use of a temporal three alarm signal (to serve as both the alert and the warning signal in case of fire emergencies) (e.g., Ball and Bruck 2004). If the building manager chooses an audible alert system for the building, it should be tested for its success in getting occupants' attention in the event of an emergency ${ }^{4}$. Additionally, the building's alert system (in addition to the warning system) should be used as part of the buildingwide training, so that the occupants are familiar with its sounds and in turn, its meaning.

Visual alerts can also be provided. The literature has reached consensus on two main ways in which to provide a visual alert before disseminating a warning message. First, a signal word (e.g., "Alert”) can be displayed to let occupants know that a visual warning message is to follow (Dudek et al. 1978). The same research suggests that the signal word, as part of a visual warning message, can be displayed in a different color (than the warning message and any other nonemergency messages posted prior) to attract attention and ensure that occupants read that signal word before any other information.

Additionally, a large amount of research in both fire and other types of emergencies have found that flashing lights, rather than static lighting can attract people's attention to an emergency (Nilsson and Frantzich 2004; Jin 2002). Currently, many buildings are equipped with strobe lights to attract people's attention to a fire emergency in the building. Strobe lights are especially useful for individuals who are hearing impaired and/or cannot hear the fire alarm or voice communication system. Flashing lights can also attract attention to visual signs used to display emergency warning messages throughout the building or building campus (i.e., outdoor signage) (Wogalter, Conzola and Smith-Jackson 2002). However, much debate exists around the appropriate color of the flashing lights. Green flashing lights, possibly due to the color of European exit signs and their meaning of safety, have been found to be successful in leading occupants to exits in wayfinding experiments in Sweden (Nilsson, Frantzich, and Saunders 2009). This guidance document does not suggest one color over another for flashing lights near visual signage due to contradictions in the research and factors that may cloud color interpretation (e.g., Mayhorn 2005), including color-blindness, old age, and cultural differences related to color meaning. The important suggestion here is the use of flashing rather than static lights, preferably one standard color for all buildings, to gain attention to visual warning messages.

Finally, there are additional methods (other than audible and visual means) to alert building occupants to an emergency. Depending upon the occupancy, it will be important for building managers and emergency personnel to aid in the disruption of routine activities, so that building occupants are able to pay attention to the warning to follow. Examples are provided here as ways to disrupt building activities: turning up the lights; cutting power to the television, internet, or computer screens; ending group activities (such as a movie or play/show); and terminating visual or audible distractions. Technology has also been invented for waking the hearing impaired (Thomas and Bruck 2008; National Association of the Deaf, n.d.), including various types of pillow or bed shakers, since nighttime sleeping reduces visual capabilities. Finally, social networks or face-to-face alerts (by fire wardens, for example) can provide additional means to alert people of an emergency.

\footnotetext{
${ }^{4}$ Guidance on alert and message testing will be provided in the follow-on report for this project (Year 3).
} 
No matter how successful an alert signal (e.g., alarm, alert sound, strobe light) is in gaining people's attention, the signal should not serve as the warning message. Alert signals are meant only to grab occupants' attention and notify them that a warning message is about to be provided. Some technologies are better at delivering alert signals and others are better at delivering warning messages (National Research Council 2011). For example, 90-character short message service (SMS) text messages have been used to alert building occupants and community residents of an emergency (National Research Council 2011). However, 90 characters provide only a limited amount of text to warn individuals of the emergency, and thus have been considered more like an alert, than a warning. In this case, text alerts would still need to be accompanied by a follow-up warning message or provide a place where building occupants could go for more information on the emergency at hand. One option is providing additional information on a website, but there is a possibility of overloading the site when building occupants attempt access simultaneously. Overall, it is important that each alert signal, regardless of dissemination mechanism, is accompanied by a clear, consistent, concise, and candid warning message. The guidance on warning messages is provided in the following section.

\subsection{Warnings}

Warning messages are meant to provide information to the building occupants on the state of the emergency and what they are supposed to do in response to this emergency. Warning messages should be provided after an alert signal is given and can be provided via visual or audible means. However, before such guidance on message format for visual and audible messages can be provided, it is vital to provide guidance on the content of the warning message, itself.

\subsubsection{The Message}

Regardless of the method used to disseminate the warning message, there are certain characteristics that are required of an effective warning message. Whereas demographic factors, such as gender or age, and environmental factors (such as physical cues or group dynamics) have been found to influence occupant response to an emergency, social science disaster research has shown that these factors become less influential when a warning message contains certain important characteristics (Mileti and Sorensen 1990).

\subsubsection{Message Content}

An effective warning message is one that is specific, consistent (with cues from the event as well as other messages disseminated about the emergency), certain, clear, and accurate (Mileti and Sorensen 1990). Also, a warning message should contain five important topics to ensure that building occupants have sufficient information to respond with little or no additional delay and information seeking (Chandler 2010; National Council on Disability 2009; Centers for Disease Control and Prevention 2002; Mileti and Sorensen 1990). These five topics, labeled here as the five W's of any effective warning message, are as follows: 
1. Who is providing the message? (i.e., the source of the message)

2. What should people do? (i.e., what actions occupants should take in response to the emergency and if necessary, how to take these actions)

3. When do people need to act? (i.e., in rapid-onset events, the "when" is likely to be "immediately")

4. Where is the emergency taking place? (i.e., who needs to act and who does not)

5. Why do people need to act? (including a description of the hazard and its dangers/consequences).

Whereas topics two through five discuss the emergency and what people should do in response to it, the first topic states that the message should identify the source. In other words, who is providing the message to the building occupants? It is important that the source of the message be someone who is perceived as credible by the building population; i.e., someone to which the occupants can relate or someone who is highly respected (Chandler 2010; Mileti and Sorensen 1990). Examples of possible credible sources for buildings in the United States include the local fire chief, the building manager (if known), the fire safety director, or other emergency personnel for the building (if known). Additionally, a credible source for one part of the building population may not be a credible source for others within the same population (Phillips and Morrow 2007). Building managers and emergency personnel should understand the building population and from this understanding, develop a database of possible, trusted sources. The building population could also be surveyed to identify, in their own words, possible message providers within the building.

\subsubsection{Message Order}

These 5 W's are not listed in any specific order at the moment, but are listed above to simply show the five categories that should be included in any warning message. No research consensus was reached as to the appropriate order of these five W's in an emergency message. Traffic research on visual signage suggests that message providers present the problem at the top (the "why"), the location of the problem on the second line ("the where"), and the recommended action (or the "what) on the third line, without mentioning the proper ordering of the message source or when people need to act (Ullman, Dudek and Ullman 2005). However, research in information recall suggests that the most important pieces of the message should be listed first (Covello, Minamyer and Clayton 2007; Conrad 1989), which in disaster emergencies is often the "what" or the actions that people should take in response to the emergency and how they should take these actions. With these contradictions and very little research on this issue, no specific guidance can be provided at this time about message ordering.

\subsubsection{Message Structure}

Research has been conducted that can provide guidance on the language structure of an emergency message. First, emergency messages should be written at a $6^{\text {th }}$ grade reading level or lower (Chandler 2010). A $6^{\text {th }}$ grade reading level ensures that a U.S. population can understand the emergency message, since the U.S. population currently reads at an average grade level of 10, which is often decreased by four grade levels in times of stress (Chandler 2010). Second, emergency messages should be written without the use of jargon and false cognates (i.e., words 
that are similar in another language, but mean different things) (Broersma 2009; Mayhorn 2005). Finally, the words that are used to describe the emergency can illicit different types of response i.e., words matter. There are certain types of words that can convey urgency. The use of words, like "deadly" and "danger" have been found to prompt a perception of urgency among the public (e.g., Hellier et al. 1002; Edworthy, Clift-Matthews and Crowther 1998). Additionally, the National Weather Service is testing a new framework in which they make use of certain "urgent words", such as "immediate" and "threatens", to understand their influence on community-based sheltering response in tornadoes. It will be important to monitor the results of this study and others to determine the appropriate use of urgent words in various types of emergency situations ${ }^{5}$.

There may be instances in which the type of technology used to issue warnings can limit the content of the message. Examples of these types of technology are SMS texts via cell phones, Twitter feeds (140-character limit for each tweet), smaller visual signage, pagers, and tone alert radios (i.e., the display itself). As mentioned earlier, these types of technologies can be used as alerts that lead people to other types of technology in which more information (i.e., the warning message) can be provided. These technologies can be used to alert individuals to the emergency and simply provide very basic information about the emergency, including methods on how and where to get additional information. However, in situations where there is no time to obtain additional information and the technology provides only limited message capabilities, the message writer can draft the message in a bulleted form (Wogalter, Conzola and Smith-Jackson 2002). Bulleted warnings have been found to be effective for conveying warning message information when space is limited. Each of the five topics in the warning (i.e., the 5 W's) should be separated as its own bullet point (Wogalter 2006).

\subsubsection{Multiple Messages}

Building managers and emergency personnel should anticipate the need to write more than one emergency message throughout a building disaster. Subsequent warning messages can be disseminated to provide feedback to building occupants, for example, if they are not following instructions previously given or if they become confused as to the appropriate actions to take in the emergency. One can envisage situations in which occupants follow others' actions, and these may not necessarily be the appropriate actions. Closed-circuit television (CCTV) cameras or fire wardens/monitors can be used to observe evacuee behavior, and if necessary, updated messages can help to correct inappropriate response behavior. Warning messages can also be used to update previous warning messages in situations where conditions have changed. For example, a fire can spread to other floors where evacuees were originally told to stay in place. Warning messages in this situation can be used to alter previous instructions to align with the current, most up-to-date situation. In this instance, however, it is important to tell building occupants why the action instructions (i.e., what to do in the emergency) have changed, so that they view the new message as credible.

\footnotetext{
${ }^{5}$ It should be noted that the use of "urgent words" in emergency messages should not be used for every emergency situation produced in the building. If these "urgent words" are overused in cases when an emergency does not occur or a less severe (than expected) emergency occurs, building occupants are likely to dismiss rather than develop a perception of urgency in the next disaster (when these words are used).
} 
One message type that is often forgotten in an emergency is the feedback message(s) that should be disseminated following an emergency. For rapid-onset events, there is often little time to detect the emergency and provide information about its current state (which leads to instructions on what to do). Therefore, there may be situations, for example in the case of tornadoes, where alert signals and warning messages are provided and then the emergency does not materialize. There is also the possibility that the emergency for which building occupants were warned was not as severe as originally predicted. Experts suspect that these situations, and others like it, could lead to "cry wolf" syndrome, or the possibility that building occupants would dismiss the threat of the next disaster and not follow the advised protective actions (e.g., Wang and Kapucu 2008). Even though research does not reach a consensus on the validity of "cry wolf syndrome" (Baker 1991), there are easy ways to ensure that inaction in the next disaster does not occur. One way to combat this syndrome is to provide feedback messages after the "non-event" to inform building occupants that the alert signal and warning system operated and worked as planned and the reasons why the event that was originally predicted did not occur (Mileti and Sorenson 1990). This way, the alert signal and warning system will more likely maintain credibility when the next rapid-onset disaster occurs.

Regardless of the type of message, and especially given the lack of consensus on message ordering, it is important for building managers and emergency personnel to test emergency messages with the building population (or a representative group of building occupants) before they are used. There are specific methods that one can follow to engage in message testing for building emergencies and the next edition of this guidance document will highlight specific sources for procedures to follow when testing emergency messages.

\subsubsection{Visual Warnings}

As messages are written, following the guidance provided above, another important factor in the creation of messages is the method in which they are formatted and displayed. Messages that are displayed visually will have different capabilities and limitations than those disseminated audibly. Message creators should consider different factors and make different types of decisions based upon the dissemination method. The first consideration is the type of visual technology that will be used to disseminate the messages, which can include textual visual displays, SMS text messages, computer pop-ups, email, internet websites, news (TV broadcast) or streaming broadcast over the web. Depending upon the technology chosen to display visual warning messages, guidance is provided here on message displays to enable occupants to see or notice the displayed warning, understand the warning, perceive warning credibility and risk, and respond appropriately.

\subsubsection{Noticing and Reading the Warning}

Most guidance pertaining to visual warnings was found on how to improve people's perception and attention of a visual signage display in buildings. Much of the guidance is from the traffic literature as well as human factors and ergonomics, and focuses on ways in which to improve an individual's awareness of a sign and ability to read the information presented on the sign. 


\section{Line of Sight}

Since buildings are complicated structures, it is important to place an emergency sign in a location where people will notice it and be able to read it from their original (pre-emergency) location. One reference was found on the importance of sign placement and positioning, noting that signs will be reliably conspicuous within $15^{\circ}$ of the direct line of sight (Creak 1997). The best position for signage, however, is one in which individuals can see and read it, head-on (i.e., $0^{\circ}$ from the direct line of sight).

\section{Font and Size}

Other important factors in the ability to read the text on a sign are the text font and size. First, the literature suggests a mixture of upper and lower case letters rather than the use of all capitals (Sanders and McCormick 1993), which makes the text easier to read. Secondly, several equations are provided for the relationship between letter height and viewing distance. Overall, the relationship between letter height and viewing distance is as follows (from the literature):

$\mathrm{D}=100$ (to 250$) * \mathrm{~h}$,

where " $h$ " is the height of the letter and " $\mathrm{D}$ " is the viewing distance (Rousseau, Lamson and Rogers 1998; Creak 1997). The recommended relationship for older adults with lower visual acuity is $\mathrm{D}=100 * \mathrm{~h}$, providing a more conservative result, and ensuring that a larger population will be able to read the emergency message provided by the sign for all types of building occupancies and populations. Finally, the literature provides suggestions on stroke-to-width ratios of the letters, specifically 1:5 (generally), with a ratio of 1:7 suggested for lighter letters on a darker background (Kuhn, Garvey and Pietrucha 1997). With various literature sources available on this topic, it is important for the building manager or emergency personnel to consult the ADA Standards for Accessible Design (U.S. Department of Justice 2010) for additional requirements on signage, including raised characters (for tactile warnings), font proportions, stroke thickness, character/line spacing, character height, glare, and signage location.

\section{Color and Contrast}

Additionally, the literature provides guidance on other ways for improving perception of visual warnings. Color may be an important component of visual signage and some colors have been more successful than others at grabbing people's attention. For example, green or yellow text has been found to be brighter than red text on visual signage (Rea, Ouellette and Clark 1985). However, more important than color is the contrast between the text on and the background of the sign. Research has shown that the contrast between the text and the background should be at least $30 \%$ (Dudek et al. 1978), although recommended values could be as high as at least $60 \%$ (Hablamos Juntos 2007). Finally, the use of pictorials (in lieu of or in addition to text) can also bring attention to the sign (Young 1991).

\section{Presentation}

When presenting warnings via television or other visual means, including visual signage, one basic piece of guidance is provided here so that viewers see and notice emergency information. 
Specific care should be taken by message providers to ensure that emergency information is not blocked by other signs or information. An important example is the use of closed-captioning on television and the use of emergency crawlers on the top or bottom of a screen (that do not interrupt regularly schedule programming). Captions and crawlers are often located in the same place on the television screen making it almost impossible for the hearing impaired (i.e., those most likely to use closed-captioning features) to receive emergency information (National Organization on Disability 2009). What seems like such an obvious recommendation is not always heeded in reality.

\subsubsection{Comprehending the Pictorial/Graphic, if used}

The main ways to improve message comprehension involves the development of the message itself; i.e., crafting the message at a $6^{\text {th }}$ grade reading level and neglecting the use of jargon and false cognates. However, specific guidance can be provided on ways to improve comprehension when using pictorials or graphics to present a visual warning. As an overall measure, printed text should accompany symbols or pictorials used in visual warnings (e.g., Jaynes and Boles 1990). Although some research found that accompanying text does not provide any additional help in comprehension (e.g., Burt, Henningsen and Consedine 1999), no research was found that the provision of text hinders response. Research does suggest that a minimum number of words should be used to accompany graphics (Caird et al. 1997; Schmidt and Kysor 1987). Also, if applicable, diagrams that display a series of sequential steps (that were numbered) are more successful in comprehension of a process than one single graphic (Burt, Henningsen and Consedine 1999; Caird et al. 1997).

\subsubsection{Perception of Credibility and Risk of the Visual Warning}

The literature reviewed in the previous document (Kuligowski et al. 2012) did not provide many recommendations on visual warnings to improve the credibility and risk assessment phases of the decision-making process. The literature mentions that red can be synonymous with danger and green with safety (Nilsson, Frantzich and Saunders 2005). However, the interpretation of hazardrelated colors and words, for that matter, is not consistent across different cultures, and possibly, different populations of buildings within the United States. What is likely more effective is the assignment of a different color to a word or phrase that is more important than the rest of the message. This color-contrasted word or statement will likely be read first and will be perceived as more urgent than the rest (in messages where color has not already been used for another purpose, e.g., bilingual messages) (Dudek et al. 1978). Since expert opinion suggests that the "what" or action portion of an emergency message is the most important, the "action" phrase should be contrasted with color, if any.

Additionally, a warning message can increase in perceived credibility and risk if occupants are shown that others are also responding (Latane and Darley 1970). This can be done, for example, by providing streaming video of the evacuation or sheltering events. A video of responding building occupants can increase trust in the warning and decrease fear or concern that they are the only ones responding. Similarly, providing updates on the emergency situation, also in the form of video (i.e., showing a video of the tornado approaching), can increase perceived credibility and risk. 


\subsubsection{Responding to the Visual Message}

Methods can be taken by creators of visual warnings to decrease response time of the greater building population. First, suggestions are made here for visual signage. Simultaneously displayed text (discrete messages), rather than a sequentially displayed message, should be used, if possible, in rapid-onset events. Simultaneously displayed messages on visual displays, if first perceived and also written for comprehension, reduce the time that occupants take to respond, which is most important in rapid-onset emergencies (Wang and Cao 2005). Simultaneously displayed text, if warranted by the population, can also be used for bilingual messages, since no difference was found in comprehension or response when presenting the bilingual message as an alternating message or a simultaneous display (of both languages). However, comprehension and response improves with simultaneously displayed bilingual messages if care is taken to differentiate the text of one language from the text of the other language, which can be done by using two different types of fonts or colors (Jamson, Tate and Jamson 2005). In either case, the use of flashing words should be limited on visual message displays, since the presence of flashing words has been shown to increase response time (Dudek and Ullman 2001).

\subsubsection{Audible Warnings}

The literature also provides guidance on the most effective ways to format audible warnings. There are specific warning technologies that only (or primarily) affect the aural sense; including public address systems (voice notification systems), automated voice dialing, satellite/AM/FM radio broadcasts, satellite/off-air television broadcasts, and tone alert radios. Whereas visual technologies can limit message length, audible warnings are often limited only by the attention capabilities of the audience. In other words, an audible message can play for long periods of time with these technology types, and the message creator and source must be careful to provide all important information in an appropriate length of time.

Similar to the organization of Section 5.2.2, this section will also be organized based upon the phases of the decision-making process. First, guidance will be given for methods to increase the likelihood that an individual will perceive, or hear the message. Then, guidance will be provided that can increase comprehension of the message for audible messages. Finally, guidance will be provided on the ways in which to increase credibility and risk assessment of the event when the warning is presented audibly.

\subsubsection{Hearing/Receiving the Audible Warning}

The literature provides some guidance on ways to improve perception of audible warnings. Similar to guidance given for audible alerts, it is important to reduce or eliminate competing voices when presenting an audible warning message. Audible messages can be provided via computerized (or synthesized) voice, pre-recorded human voice, or a live human voice.

Therefore, the reduction or elimination of other voices in the background helps individuals to hear the warning message. Additionally, research suggests that any voice announcements also be accompanied by simultaneous visual text (Stout, Heppner and Brick 2004). For example, in 
buildings, a voice announcement can be provided at the same time as an email or text message is received. This allows for a larger number of building occupants, including the hearing impaired and the visually impaired, to receive the warning message at the same time.

\subsubsection{Comprehending the Audible Warning}

Guidance is also suggested to improve occupants' comprehension of audible messages. Even though focus should be placed on message wording and creation to improve comprehension (Section 5.2.1), there are specific recommendations on format that can be made. First, some parts of the English language are more difficult to identify in speech than others. Research has shown that letters are more difficult to identify in speech, than numbers, which are more difficult than colors (Cooke, Garcia Lecumberri and Barker 2008). Therefore, labeling building exits (e.g., stairs or elevators) with numbers or colors, rather than letters, especially if exit designations are included within the emergency message, may increase message comprehension. Additionally, message speakers (or sources) should not be heavily accented and should speak with a speaking rate of approximately 175 words per minute (Dudek et al. 1978). Traffic research has shown that speaking rates of 110 words per minute or less are considered too slow and are perceived by the listening audience as unimportant (Dudek et al. 1978).

\subsubsection{Perception of Credibility and Risk of the Audible Warning}

Audible messages provide additional opportunities to influence credibility and risk perception. To increase the credibility of the message and the emergency discussed within the message, audible warnings should be delivered using a live voice. The consensus among the research gathered is that believability is more difficult to achieve with a synthesized-voice warning (Hellier et al. 2002). Since higher credibility is often assigned to a live voice, buildings may wish to use pre-recorded messages as an alert or introduction to the live warning messages that follow. In this case, it is important to have the live voice message provided by a credible source who introduces him/herself within the message and less important to assign a credible source to the pre-recorded alert message. However, in cases when only pre-recorded voice messages are given in the building, the message should be recorded by a credible message source. One note of caution: if the same recorded message plays too often in building events where no emergency occurs, the credibility attributed to this recording (and the message source) may decrease over time.

Credibility is not the only benefit offered by live voice messages. Live messages can be updated with new information and can be used to convey an appropriate level of urgency, if necessary (Proulx 2001). The ways in which urgency can be achieved via a voice message is either by increasing the speech rate (which contradicts the earlier recommendation to speak at a normallypaced speech rate for comprehension purposes) or by projecting a higher-pitched voice. Gender matters less here, than the pitch of the voice; however, in most cases, women have voices that are higher in pitch.

One note should be made about conveying urgency in audible messages. The literature from a variety of disciplines provides insight on the various methods that can be used to convey urgency in alerts and warnings. As mentioned earlier, for example, urgency can be conveyed in alert 
signals through the use of quick pulses. Additionally, warnings using a higher-pitched voice or a faster speech rate, or crafted using certain words, colors or graphics can also convey urgency levels. However, there is little mention in the disaster/fire research literature on whether it is appropriate to convey urgency in emergency messaging. The human factors and ergonomics literature suggests that warnings and alarms should convey the level of urgency of the situation (Edworthy 1998); however, other disciplines remain silent on the issue. Since overuse of urgency, especially in situations where emergencies are downgraded or do not materialize, may likely lead to non-response in future disasters, urgency measures should be used selectively to emphasize the more dangerous, immediate, life-threatening situations.

\subsubsection{Dissemination of the Warning Message}

Research has shown that individuals are information seekers in times of disaster. Therefore, it is important to ensure that the entire population receives (and pays attention to) the alerts and warning messages as soon as possible.

\subsubsection{Multiple Channels}

One way to reach the entire population of the building or building campus is to use multiple channels to disseminate the warning message - including visual means, audible means, and tactile means. Examples of tactile means for the hearing impaired includes vibrating pagers and text messages, and for the visually impaired, raised characters or Braille on building signage. It is important for message providers to understand the messaging needs of their occupants in order to design an emergency communication system with the appropriate technology and credible message sources to reach all sub-groups within the building.

\subsubsection{Message Repetition}

Another way to reach the entire building population is through message repetition. A warning message should be repeated at least once, with some research advocating for message repetition of at least two times (Dudek et al. 1978; Huchingson, Koppa and Dudek 1978). Additionally, messages should be stated, in full, and then repeated, in full - rather than repeating statements within the same message. Research has found more success in recalling the message when the entire message was repeated over again, multiple times (Huchingson, Koppa and Dudek 1978). Finally, warning messages should be repeated at intervals, rather than consecutively (Melton 1970). The second (or third message), provided some interval of time later, may catch a different population who were either busy or distracted during the time period when the first warning message was issued.

\subsubsection{Timing}

Warning messages should also be disseminated as early as possible. This way, building occupants are provided with enough time to take protection before untenable conditions occur. Also, face-to-face communication should accompany other audible or visual technologies, due to its success in prompting occupant response during emergencies. 


\subsubsection{Communication Type}

The last point related to dissemination of warnings refers to the operation of warning technology. Guidance suggests that messages should be disseminated using a combination of both push and pull technologies (Chandler 2010). Push technologies are those that do not require individuals to take extra effort to receive the alert or warning message (e.g., public address systems or text messages); whereas pull technologies require the individual to seek additional information to acquire the alert/message (e.g., internet websites). Push communication is most important to use for alert signals as well as initial warning messages, since building occupants often require awareness of the incident in its initial stages. Then, once initial information is made available via push communication, additional information can be provided by both push and pull technologies.

\subsection{Summary of Guidance}

Table 2 provides a summary of the guidance offered above on both alerts and warning messages. The guidance is organized by the type of emergency communication (alert versus warnings) and then by the main topics that were used for organization, above.

Table 2: Summary of guidance on alerts and warning messages

\begin{tabular}{|c|c|c|}
\hline $\begin{array}{c}\text { Communication } \\
\text { Topic } \\
\end{array}$ & $\begin{array}{l}\text { Section of } \\
\text { Report }\end{array}$ & Guidance statement \\
\hline \multicolumn{3}{|l|}{ Alerts } \\
\hline & 5.1 & Alerts should be significantly different from ambient sounds \\
\hline & & Buildings should reduce background noise when initiating audible alerts \\
\hline & & $\begin{array}{l}\text { If chosen, an alert should be tested for its success in getting occupants' } \\
\text { attention in the event of an emergency and used as part of the building-wide } \\
\text { training. }\end{array}$ \\
\hline & & $\begin{array}{l}\text { Flashing rather than static lights, preferably one standard color for all } \\
\text { buildings, can be used to gain attention to visual warning messages }\end{array}$ \\
\hline & & $\begin{array}{l}\text { There are additional methods to alert building occupants to an emergency: } \\
\text { disruption of routine activities, tactile methods, social networks, face-to-face }\end{array}$ \\
\hline & & $\begin{array}{l}\text { An alert signal should be accompanied by a clear, consistent, concise, and } \\
\text { candid warning message }\end{array}$ \\
\hline \multicolumn{3}{|c|}{ Warnings - The message } \\
\hline & 5.2 .1 .1 & $\begin{array}{l}\text { A warning message should contain five important topics to ensure that } \\
\text { building occupants have sufficient information to respond } \\
\text { 1. Who is providing the message? (i.e., the source of the message) } \\
\text { 2. What should people do? (i.e., what actions occupants should take in } \\
\text { response to the emergency and if necessary, how to take these actions) } \\
\text { 3. When do people need to act? (i.e., in rapid-onset events, the "when" is } \\
\text { likely to be "immediately") } \\
\text { 4. Where is the emergency taking place? (i.e., who needs to act and who } \\
\text { does not) } \\
\text { 5. Why do people need to act? (including a description of the hazard and } \\
\text { its dangers/consequences) }\end{array}$ \\
\hline & & $\begin{array}{l}\text { The source of the message should be someone who is perceived as credible } \\
\text { by the building population }\end{array}$ \\
\hline & & $\begin{array}{l}\text { Building managers and emergency personnel should understand the building } \\
\text { population and from this understanding, develop a database of possible, } \\
\text { trusted sources }\end{array}$ \\
\hline & 5.2 .1 .3 & Emergency messages should be written at a $6^{\text {th }}$ grade reading level or lower \\
\hline
\end{tabular}




\begin{tabular}{|c|c|c|}
\hline $\begin{array}{c}\text { Communication } \\
\text { Topic }\end{array}$ & $\begin{array}{c}\text { Section of } \\
\text { Report }\end{array}$ & Guidance statement \\
\hline \multicolumn{3}{|c|}{ Warnings - The message, continued } \\
\hline & 5.2.1.3, cont. & $\begin{array}{l}\text { Emergency messages should be written without the use of jargon and false } \\
\text { cognates }\end{array}$ \\
\hline & & $\begin{array}{l}\text { For limited message length, message writers could draft the message in a } \\
\text { bulleted form; each of the five topics in the warning should be separated as } \\
\text { its own bullet point }\end{array}$ \\
\hline & 5.2 .1 .4 & $\begin{array}{l}\text { Building managers and emergency personnel should anticipate the need to } \\
\text { write more than one emergency message throughout a building disaster: } \\
\text { feedback messages or updates, for example }\end{array}$ \\
\hline & & $\begin{array}{l}\text { In update messages, tell building occupants why the information has } \\
\text { changed, so that the new message is viewed as credible }\end{array}$ \\
\hline & & $\begin{array}{l}\text { Provide feedback messages after a "non-event" to inform building occupants } \\
\text { that the alert signal and warning system operated and worked as planned and } \\
\text { the reasons why the event did not occur }\end{array}$ \\
\hline & & $\begin{array}{l}\text { Building managers and emergency personnel should test emergency } \\
\text { messages with the building population }\end{array}$ \\
\hline \multicolumn{3}{|c|}{ Warnings - Visual } \\
\hline & $\begin{array}{l}\text { 5.2.2.1 (Line } \\
\text { of sight) }\end{array}$ & $\begin{array}{l}\text { Place the emergency sign in a location where people will notice it and be } \\
\text { able to read it from their original (pre-emergency) location }\end{array}$ \\
\hline & & $\begin{array}{l}\text { Signs will be reliably conspicuous within } 15 \text { degrees of the direct line of } \\
\text { sight }\end{array}$ \\
\hline & (Font and size) & $\begin{array}{l}\text { Text is easier to read when written with a mixture of upper and lower case } \\
\text { letters rather than the use of all capitals }\end{array}$ \\
\hline & & $\begin{array}{l}\text { The recommended relationship for older adults with lower visual acuity is D } \\
=100 * \text { h, providing a more conservative result, and ensuring that a larger } \\
\text { population will be able to read the emergency message }\end{array}$ \\
\hline & & $\begin{array}{l}\text { A stroke-to-width ratios of the letters is suggested as 1:5 (generally), with a } \\
\text { ratio of 1:7 suggested for lighter letters on a darker background }\end{array}$ \\
\hline & & $\begin{array}{l}\text { Building managers or emergency personnel should consult the ADA } \\
\text { Standards for Accessible Design (U.S. Department of Justice 2010) for } \\
\text { additional requirements on signage }\end{array}$ \\
\hline & $\begin{array}{l}\text { (Color and } \\
\text { contrast) }\end{array}$ & $\begin{array}{l}\text { Contrast between the text and the background should be at least } 30 \% \text {, } \\
\text { although recommended values could be as high as at least } 60 \%\end{array}$ \\
\hline & & $\begin{array}{l}\text { The use of pictorials (in lieu of or in addition to text) can also bring attention } \\
\text { to the sign }\end{array}$ \\
\hline & (Presentation) & $\begin{array}{l}\text { Message providers should ensure that emergency information is not blocked } \\
\text { by other signs or information }\end{array}$ \\
\hline & 5.2 .2 .2 & $\begin{array}{l}\text { Printed text should accompany symbols or pictorials used in visual warnings; } \\
\text { a minimum number of words should be used to accompany graphics }\end{array}$ \\
\hline & & $\begin{array}{l}\text { Diagrams that display a series of sequential steps are more successful in } \\
\text { comprehension of a process than one single graphic }\end{array}$ \\
\hline & 5.2 .2 .3 & $\begin{array}{l}\text { Use a color-contrasted word or statement for text that should be read first } \\
\text { and/or be perceived as more urgent than the rest; unless color is used for } \\
\text { other reasons (e.g., bilingual text) }\end{array}$ \\
\hline & & $\begin{array}{l}\text { A warning message can increase in perceived credibility and risk if } \\
\text { occupants are shown that others are also responding }\end{array}$ \\
\hline & 5.2 .2 .4 & $\begin{array}{l}\text { Simultaneously displayed text (discrete messages), rather than a sequentially } \\
\text { displayed message, should be used }\end{array}$ \\
\hline & & $\begin{array}{l}\text { Simultaneously displayed text can also be used for bilingual messages, } \\
\text { especially if care is taken to differentiate the text of one language from the } \\
\text { text of the other language }\end{array}$ \\
\hline & & Limit the use of flashing words on visual message displays \\
\hline
\end{tabular}




\begin{tabular}{|c|c|c|}
\hline $\begin{array}{c}\text { Communication } \\
\text { Topic }\end{array}$ & $\begin{array}{l}\text { Section of } \\
\text { Report }\end{array}$ & Guidance statement \\
\hline \multicolumn{3}{|c|}{ Warnings - Audible } \\
\hline & 5.2.3.1 & $\begin{array}{l}\text { Other, non-alert/warning voices in the background should be reduced or } \\
\text { eliminated }\end{array}$ \\
\hline & & $\begin{array}{l}\text { Any voice announcements should also be accompanied by simultaneous } \\
\text { visual text }\end{array}$ \\
\hline & 5.2 .3 .2 & $\begin{array}{l}\text { Letters are more difficult to identify in speech, than numbers, which are } \\
\text { more difficult than colors }\end{array}$ \\
\hline & & $\begin{array}{l}\text { Message speakers (or sources) should not be heavily accented and should } \\
\text { speak with a speaking rate of approximately } 175 \text { words per minute }\end{array}$ \\
\hline & & Audible warnings should be delivered using a live voice \\
\hline & & $\begin{array}{l}\text { Other benefits are provided by a live voice method: messages can be updated } \\
\text { with new information and can be used to convey an appropriate level of } \\
\text { urgency, if necessary }\end{array}$ \\
\hline & & $\begin{array}{l}\text { Urgency measures should be used selectively to emphasize the more } \\
\text { dangerous, immediate, life-threatening situations (since overuse may likely } \\
\text { lead to non-response in future disasters) }\end{array}$ \\
\hline \multicolumn{3}{|c|}{ Warnings - Dissemination } \\
\hline & 5.2.4.1 & $\begin{array}{l}\text { Use multiple channels to disseminate the warning message - including visual } \\
\text { means, audible means, and tactile means }\end{array}$ \\
\hline & 5.2 .4 .2 & $\begin{array}{l}\text { A warning message should be repeated at least once, with some research } \\
\text { advocating for message repetition of at least two times }\end{array}$ \\
\hline & & $\begin{array}{l}\text { Additionally, messages should be stated, in full, and then repeated, in full - } \\
\text { rather than repeating statements within the same message }\end{array}$ \\
\hline & & Warning messages should be repeated at intervals, rather than consecutively \\
\hline & 5.2 .4 .3 & Warning messages should also be disseminated as early as possible \\
\hline & & $\begin{array}{l}\text { Face-to-face communication should accompany other audible or visual } \\
\text { technologies }\end{array}$ \\
\hline & 5.2.4.4 & $\begin{array}{l}\text { Messages should be disseminated using a combination of both push and pull } \\
\text { technologies }\end{array}$ \\
\hline & & $\begin{array}{l}\text { Push communication is most important to use for alert signals as well as } \\
\text { initial warning messages }\end{array}$ \\
\hline
\end{tabular}

\section{Questions Left Unanswered}

As mentioned in Section 2, the development of this guidance document has shed light on research findings that are either conflicting (between or within disciplines) or areas of the field that remain unexplored. This section represents a discussion of "the things we know we do not know."

Conflicting research and guidance exist on the appropriate length of emergency messages. Some findings state that messages should be no more than 30 words long, a total of three sentences and last for approximately 9 seconds (Chandler 2010; Centers for Disease Control and Prevention 2002). However, this guidance is often offered for events where the audience is not already paying attention, and in a disaster event, once people are made aware that something is going on, they are likely to stay tuned to information sources to find out more information. With that said, 
there is no additional guidance on a maximum message length for disaster-related warning information provided in building emergencies, especially for technologies where there is no fixed limit on message length (e.g., email, public address systems, etc). There is also no additional guidance on the appropriate length of audibly-provided pre-recorded messages versus live messages, although the guidance document does state the benefits of using live voice messages over a pre-recorded voice. Overall, messages should not be so long that they delay occupants taking protective action, but should be long enough to convey the appropriate information necessary to prompt response (i.e., the five topics listed in 5.2.1.1).

An additional topic that requires further research is the ordering of warning message content. Traffic research provides one suggestion: the problem statement (or information on the disaster) should be provided first, followed by the location of the problem, then, ending with the action statement (i.e., instructions on what individuals should do in response to the problem). However, disaster research does not provide specific guidance on this to either confirm or refute this suggested message order. It will be important to test message order in future disasters to determine if message order matters and if so, the appropriate order for rapid-onset emergency warnings.

No consensus was reached on the appropriate number of repetitions required for the emergency warning message. Most studies reported on the number of repetitions that would aid in recall; however, in a disaster, recall is less important than ensuring that the message is received (and paid attention to) by as many occupants in the building as possible. This guidance document suggests that the message is repeated at least one time, on an interval basis (rather than successive) to increase the number of individuals in the building who receive the message; however, more research should be performed on message repetition.

Finally, one finding on alerts warrants discussion: alerts should sound differently for different types of emergencies (U.S. Department of Justice 2010). This finding is not included in the guidance document because of the unnecessary burden this places on building occupants. Designing a communication system that sounds differently for each building emergency would require occupants to learn and remember a potentially complicated alert system. Using the alert/warning system described in Section 5, a building should use one consistent alert signal to get people's attention to a building emergency situation, which should then be followed by an expertly crafted and tested warning message specific to the emergency. Currently, in buildings without a voice communication system, the fire alarm serves as both the alert and the warning system, and for this reason, fire researchers have advocated for a standardized fire alarm signal so that individuals from building to building understand what that signal means. However, if the building uses an alert system followed by an appropriate warning message, this is an even better way to get individuals to respond safely and effectively to the building emergency.

\section{$7 \quad$ Future Work}

The next step in this project is to develop emergency-specific guidance for message providers; i.e., guidance that will focus on the development of messages based upon building emergency type and technology used to disseminate the message. Message templates will be created that 
provide examples of how to formulate messages for different types of emergencies as well as the limitations associated with a range of technologies (e.g., voice communication versus text messaging). This is a very important section of the guidance document since many guidance document users (e.g., building emergency managers) will require examples of how to formulate messages to meet the varying needs of their building population. Common messaging practices across all buildings should enhance familiarity with message type and meaning, and thereby improve the effectiveness of alerts and warnings nationwide. In addition, guidance will also be provided on the importance of message testing and how to perform such tests after messages have been written. 


\section{References}

American National Standards Institute. (2011). ANSI/NEMA Z535.3-2011, Criteria for safety symbols. New York: American National Standards Institute.

Ball M, Bruck D. (2004, September). The Effect of Alcohol Upon Response to Fire Alarm Signals in Sleeping Young Adults. Proceedings of the Third International Symposium on Human Behaviour in Fire. Belfast, Northern Ireland. J Shields (Ed.), Interscience Communications, London, UK, 291-302.

Baker EJ. (1991, August). Hurricane Evacuation Behavior. International Journal of Mass Emergencies and Disasters, 9(2), 287-310.

British Standard BS 5839-8:2008. (2008). Fire Detection and Fire Alarm Systems for Buildings - Part 8: Code of practice for the design, installation, commissioning and maintenance of voice alarm systems.

Broersma M. (2009). Triggered codeswitching between cognate languages. Bilingualism: Language and Cognition, 12(4), 447-462.

Burt CDB, Henningsen N, Consedine N. (1999). Prompting correct lifting posture using signs. Applied Ergonomics, 30(4), 353-359.

Caird JK, Wheat B, McIntosh KR, Dewar RE. (1997). The comprehensibility of airline safety card pictorials. Proceedings of the Human Factors and Ergonomics Society $41^{\text {st }}$ Annual Meeting Vol 2, 801-805.

Centers for Disease Control and Prevention. (2002, September). Crisis and emergency risk communication. Washington, DC: CDC.

Online course: http://emergency.cdc.gov/cerc/CERConline/index2.html.

Chandler, R. (2010). Emergency Notification. Santa Barbara: Praeger.

Conrad L. (1989). The effects of time-compressed speech on native and EFL listening comprehension. Studies in Second Language Acquisition, 11, 1-16.

Cooke M, Garcia Lecumberri, ML, Barker J. (2008, January). The foreign language cocktail party problem: Energetic and informational masking effects in non-native speech perception. The Journal of the Acoustical Society of America, 123(1), 414-427.

Covello V, Minamyer S, Clayton K. (2007, March). Effective risk and crisis communication during water security emergencies: Summary report of EPA sponsored message mapping workshops (Report No. EPA/600/R-07/027). Washington, DC: U.S. Environmental Protection Agency.

http://cfpub.epa.gov/si/si_public_record_report.cfm?address=nhsrc/\&dirEntryId=165863. 
Creak J. (1997). About Viewing Distances. Means of Escape (Article 549).

http://www.means-of-escape.com/articles/549/about-viewing-distances/

Drabek, T. E. (1986). Human System Responses to Disaster: An Inventory of Sociological Findings. New York, NY: Springer-Verlag.

Drabek, Thomas E. 1969. "Social Processes in Disaster: Family evacuation.” Social Problems 16(3): 336-349.

Dudek CL, Ullman GL. (2001, November). Guidelines for changeable message sign messages: Annotated bibliography (DTFH61-96-C-00048). Texas Transportation Institute, College Station, TX.

Dudek CL, Huchingson RD, Stockton WR, Koppa RJ, Richards SH, Mast TM. (1978, September). Human factors requirements for real-time motorist information displays, Volume 1 - Design Guide (U.S. Department of Transportation Report No. FHWA-RD-78-5). Texas Transportation Institute, College Station, TX.

Edworthy J. (1998). What makes a good alarm? IEE Colloquium Digest on 'Medical Equipment Alarms: The Need, the Standards, the Evidence' (pp. 5-8). Ref. No 1998/432, The Institution of Electrical Engineers.

Edworthy J, Clift-Matthews W, Crowther M. (1998). Listener's understanding of warning signal words. In MA Hanson (Ed.), Contemporary Ergonomics 1998: Proceedings of the Annual Conference of the Ergonomics Society (pp. 316-320). London, UK: Taylor \& Francis.

Groner, N. (2009). A Situation Awareness Analysis for the Use of Elevators During Fire Emergencies. In 4th International Symposium on Human Behavior in Fire: Conference Proceedings (pp. 61-72). London: Interscience Communications Ltd.

Gwynne, S. M. V. (2007). Optimizing Fire Alarm Notification for High Risk Groups. Quincy, MA: The Fire Protection Research Foundation.

Haas EC, Casali JG. (1995). Perceived urgency of and response time to multi-tone and frequency-modulated warning signals in broadband noise. Ergonomics, 38(11), 2313-2326.

Haas EC, Edworthy J. (1996, August). Designing urgency into auditory warnings using pitch, speed, and loudness. Computing \& Control Engineering Journal, 7(4), 193-198.

Hablamos Juntos. Using Universal Symbols: Improving wayfinding through universal signage systems. (2007, March). Environment of Care News, 8-10.

Hellier E, Edworthy J, Weedon B, Walters K, Adams A. (2002, Spring). The perceived urgency of speech warnings: Semantics versus acoustics. Human Factors: The Journal of the Human Factors and Ergonomics Society 44(1), 1-17. 
Huchingson RD, Koppa RJ, Dudek CL. (1978). Human factors requirements for real-time motorist information displays, Vol. 13: Human factors evaluation of audio and mixed model variables (Report No. FHWA-RD-78-17). Washington, DC: U.S. Department of Transportation.

ISO. (2011). ISO 7010:2011 Graphical symbols - Safety colours and safety signs - Registered safety signs. Pp. 124.

ISO. (2007). ISO 7001 Graphical Symbols - Public information symbols. Pp. 56.

ISO. (2004). ISO 16069 Graphical Symbols - Safety signs - Safety way guidance systems (SWGS). Pp. 51

Jamson SL, Tate FN, Jamson AH. (2005). Evaluating the effects of bilingual traffic signs on driver performance and safety. Ergonomics, 48(15), 1734-1748.

Jaynes LS, Boles DB. (1990). The effect of symbols on warning compliance. Proceedings of the Human Factors Society $34^{\text {th }}$ Annual Meeting, Santa Monica, CA, 984-987.

Jin T. (2002). Visibility and human behavior in fire smoke. The SFPE Handbook of Fire Protection Engineering (3rd Edition), Eds: PJ DiNenno et al., National Fire Protection Association, Quincy, MA, pp. (2-42)-(2-54).

Kuligowski, E. D. (2011). Terror Defeated: Occupant sensemaking, decision-making and protective action in the 2001 World Trade Center disaster. Ph.D. Dissertation. Boulder, CO: University of Colorado at Boulder.

Kuligowski, E.D., S.M.V. Gwynne, K.M. Butler, B.L. Hoskins, and C.R. Sandler. (2012) Developing Emergency Communication Strategies for Buildings. Technical Note 1733, National Institute of Standards and Technology: Gaithersburg, MD.

Kuhn BT, Garvey PM, Pietrucha MT. (1997). Model guidelines for visibility of on-premise advertisement signs. Transportation Research Record, 1605, 80-87.

Kunreuther, H. (1991). A Conceptual Framework for Managing Low Probability Events. Philadelphia, PA: Center for Risk and Decision Processes, University of Pennsylvania.

Latane, Bibb and John M. Darley. 1970. The Unresponsive Bystander: Why doesn't he help? New York, NY: Appleton-Century Crofts.

Lindell, M. K. and R. W. Perry. (2004). Communicating Environmental Risk in Multiethnic Communities. Sage Publications.

Mayhorn CB. (2005, November). Cognitive aging and the processing of hazard information and disaster warnings. Natural Hazards Review, 6(4), 165-170.

Melton AW. (1970, October). The situation with respect to the spacing of repetitions and 
memory. Journal of Verbal Learning and Verbal Behavior, 9(5), 596-606.

Mileti, D. S. and J. H. Sorensen. (1990). Communication of Emergency Public Warnings. ORNL-6609, Oak Ridge: National Laboratory.

National Council on Disability. (2009, August). Effective emergency management: Making improvements for communities and people with disabilities. Washington, DC: NCD. http://www.ncd.gov/publications/2009/Aug122009

National Association of the Deaf. (n.d.). Emergency warnings: Notification of deaf or hard of hearing people. Silver Spring, MD: NAD(Author).

http://tap.gallaudet.edu/emergency/nov05conference/EmergencyReports/NADEmergency.doc

National Fire Protection Association. (2013). NFPA 72 US National Fire Alarm and Signaling Code. Quincy: National Fire Protection Association.

National Fire Protection Association. (2012). NFPA 170 Standard for Fire Safety and Emergency Symbols. Quincy: National Fire Protection Association.

National Fire Protection Association. (2010a). NFPA 72 US National Fire Alarm and Signaling Code. Quincy: National Fire Protection Association.

National Fire Protection Association. (2010b). NFPA 1600, Standard on Disaster/Emergency Management and Business Continuity Programs. Quincy: National Fire Protection Association.

National Research Council. (2011). Public response to alerts and warnings on mobile devices: Summary of a workshop on current knowledge and research gaps. Washington, DC: The National Academies Press.

Nilsson D, Frantzich H. (2004). Evacuation experiments in a smoke-filled tunnel. Proceedings of the 3rd Human Behavior in Fire Symposium, Belfast, UK, 229-238.

Nilsson D, Frantzich H, Saunders WL. (2009). Influencing exit choice in the event of a fire evacuation. Fire Safety Science- Proceedings of the Ninth International Symposium, 341-352.

Nilsson D, Frantzich H, Saunders W. (2005). Coloured flashing lights to mark emergency exits Experiences from evacuation experiments. Proceedings of the Eighth International Symposium on Fire Safety Science, 569-579.

Okabe, K. and S. Mikami. (1982). A Study on the Socio-Psychological Effect of a False Warning of the Tokai Earthquake in Japan. A Paper presented at the Tenth World Congress of Sociology, Mexico City, Mexico.

Quarantelli, E. L. and R. R. Dynes. (1972). "When Disaster Strikes (It Isn't Much Like What You've Heard and Read About)” Psychology Today 5(February): 67-70. 
Perry, R. W., M. K. Lindell, and M. R. Greene. (1981). Evacuation Planning in Emergency Management. Lexington, MA: Lexington Books.

Phillips BD, Morrow BH. (2007, August). Social science research needs: Focus on vulnerable populations, forecasting, and warnings. Natural Hazards Review, 8(3), 61-68.

Proulx G. (2001, May). Occupant behaviour and evacuation. Proceedings of the 9th International Fire Protection Symposium, Munich, Germany, 219-232.

Rea MS, Ouellette MJ, Clark FRS. (1985). Design considerations for egress signs based upon visibility through smoke. General Proceedings of AIA Research \& Design 85, Architectural Applications of Design and Technology Research, American Institute of Architects, Washington, DC, 295-297; also (Report No. NRCC 25185), National Research Council of Canada, Ottawa, Canada.

Rousseau GK, Lamson N, Rogers WA. (1998). Designing warnings to compensate for agerelated changes in perceptual and cognitive abilities. Psychology \& Marketing, 15(7), 643-662.

Sanders MM, McCormick EJ. (1993). Chapter 4: Text, Graphics, Symbols and Codes. In Human Factors in Engineering and Design ( $7^{\text {th }}$ ed.) (pp. 91-128). New York: McGraw-Hill.

Schmidt JK, Kysor KP. (1987). Designing airline passenger safety cards. Proceedings of the Human Factors Society $31^{\text {st }}$ Annual Meeting, 51-55.

Stout C, Heppner CA, Brick K. (2004, December). Emergency preparedness and emergency communication access: Lessons learned since 9/11 and recommendations. Deaf and Hard of Hearing Consumer Advocacy Network (DHHCAN) and Northern Virginia Resource Center for Deaf and Hard of Hearing Persons (NVRC). http://tap.gallaudet.edu/Emergency/Nov05Conference/EmergencyReports/DHHCANEmergency $\underline{\text { Report.pdf }}$

Thomas IR, Bruck D. (2008). Strobe lights, pillow shakers and bed shakers as smoke alarm signals. Fire Safety Science-Proceedings of the Ninth International Symposium, Karlsruhe, Germany, 415-423.

Tierney, K. J. (2003). "Disaster Beliefs and Institutional Interests: Recycling disaster myths in the aftermath of 9-11.” Pp. 33-51 in Terrorism and Disaster: New Threats, New Ideas (Research in Social Problems and Public Policy, Volume 11), edited by Ted I. K. Youn. Bingley, UK: Emerald Group Publishing Limited.

Tierney, K. J., M. K. Lindell, and R. W. Perry. (2001). Facing the Unexpected: Disaster Preparedness and Response in the United States. Joseph Henry Press.

Timmons RP. (2009). Sensory overload as a factor in crisis decision-making and communications by emergency first responders. $\mathrm{PhD}$ dissertation, The University of Texas at 
Dallas.

Timmons RP. (2007, February). Interoperability: Stop Blaming the Radio. Homeland Security Affairs, III(1), 1-17.

Ullman GL, Dudek CL, Ullman BR. (2005, September). Development of a field guide for portable changeable message sign use in work zones (Texas Department of Transportation Report No. FHWA/TX-06/0-4748-2). Texas Transportation Institute, College Station, TX.

U.S. Department of Justice. (2010, September). 2010 ADA Standards for Accessible Design. Washington, DC: DOJ (Author). http://www.ada.gov/2010ADAstandards_index.htm

Wang XH, Kapucu N. (2008). Public complacency under repeated emergency threats: Some empirical evidence. Journal of Public Administration Research and Theory, 18(1), 57-78.

Wang J-H, Cao Y. (2005). Assessing Message Display Formats of Portable Variable Message Signs. Transportation Research Record: Journal of the Transportation Research Board, 1937, 113-119.

Wogalter MS. (2006). Purposes and scope of warnings. In MS Wogalter (Ed.), Handbook of Warnings (pp. 3-9). Mahwah, NJ: Lawrence Erlbaum Associates, Inc.

Wogalter MS, Conzola VC, Smith-Jackson TL. (2002). Research-based guidelines for warning design and evaluation. Applied Ergonomics, 33(3), 219-230.

Young SL. (1991). Increasing the noticeability of warnings: Effects of pictorial, color, signal icon and border. Proceedings of the Human Factors Society $35^{\text {th }}$ Annual Meeting, 580-584. 